\title{
Perceptions of Chinese Stakeholders on the Disclosure Importance of Intellectual Capital Attributes: A Note
}

\author{
Yi An ${ }^{1}$, Harun Harun ${ }^{2}$, Chunhui $\mathrm{Hu}^{1} \&$ Xuehua $\mathrm{Liu}^{1}$ \\ ${ }^{1}$ College of Management, Ocean University of China, China \\ ${ }^{2}$ Faculty of Business, Government and Law, University of Canberra, Canberra, Australia \\ Correspondence: Yi An, College of Management, Ocean University of China, 238 Songling Road, Laoshan \\ District, Qingdao City, China. E-mail: ryson9696@hotmail.com
}

Received: September 15, 2014

Accepted: October 29, 2014

Online Published: November 22, 2014

doi:10.5539/ijbm.v9n12p105

URL: http://dx.doi.org/10.5539/ijbm.v9n12p105

\begin{abstract}
The aim of this study is to examine the perceptions of Chinese stakeholders on the disclosure importance of the most significant intellectual capital (IC) attributes by firms, primarily using a questionnaire survey. It proceeded in two stages. In the first stage, a number of IC attributes were selected on the basis of prior literature and a consultation process with a panel of Chinese stakeholders. In the second stage, a questionnaire survey was designed to gather the opinions of the stakeholder panel on the disclosure importance of the identified IC attributes. The results show that all the attributes achieved a rating at least moderately important, including $60 \%$ rated as extremely or very important to disclose. In addition, the stakeholders offered some insightful comments and suggestions on the disclosure of IC in China.
\end{abstract}

Keywords: IC attributes, stakeholders, perceptions, disclosure importance, China

\section{Introduction}

Intellectual capital (IC), including such elements as research \& development (R\&D), intellectual property, brands, reputation, customer satisfaction, employee competences, etc., is often regarded as a core resource for companies to achieve and sustain a competitive advantage in the current knowledge economy (Stewart, 1997; Nahapiet \& Ghoshal, 1998; Yi \& Davey, 2010). Due to the importance of IC elements for value creation, increasing companies attempt to disclose IC-related information in their annual reports (or IPOs or websites) in order to highlight their excellence and attract potential investors.

There has been considerable research investigating the status of IC disclosure in a particular country or industry (i.e. Abeysekera \& Guthrie, 2005; Oliveira et al., 2006; Li et al., 2008; White et al., 2010; Rashid et al., 2012). Differing from the prior research, our paper examines the perceptions of Chinese stakeholders on the disclosure importance of the most significant IC attributes, using a questionnaire survey into a panel of Chinese stakeholders. The findings indicate that all the attributes were rated at least moderately important, including $60 \%$ rated as extremely or very important to disclose. In addition, the panellists offered some insightful comments and suggestions in the survey, which were considered to be very helpful to gain a deeper comprehension regarding the perceptions of Chinese stakeholders on IC disclosure in the Chinese context.

The remainder of the paper is structured as follows. Section 2 presents a literature review regarding the importance of disclosure items in corporate annual reports. Section 3 and 4 describe the research method and results. The final section summarizes the research findings and draws some conclusions.

\section{Literature Review}

To determine the importance for disclosure items, many previous studies focused on one user group of the annual report (usually financial analysts or investors) for their opinions on the relative importance of the items (Hooks, 2000). More recently, a few studies, such as Hooks et al. (2002), Coy and Dixon (2004), Schneider and Samkin (2008), and Khan and Ali (2010), add a stakeholder focus to research. In these studies, the researchers employ various user groups that represent a wider range of stakeholder groups through incorporating their views to weigh disclosure items. For instance, Hooks et al. (2002) used sixteen stakeholders/users (Note 1) to assess importance of financial disclosure items in the electricity industry while Schneider and Samkin (2008) employed 
four stakeholder groups (Note 2) to evaluate disclosure importance of IC attributes in the local government sector.

According to Hooks (2000, p. 128), "the weightings (namely importance of disclosure items) result from feedback from a wide range of stakeholders so that the bias that would be imposed by just one-user group, for example, financial analysts, is avoided and may be eliminated." Furthermore, pursuant to stakeholder theory, organizations should attempt to meet multiple expectations of a wide range of stakeholders (Donaldson and Preston, 1995; Freeman et al., 2004). Disclosure of IC-related information is often regarded as one of the most effective means for organizations to discharge their accountability to various stakeholders in society (Roberts, 1992; An et al., 2011). Hence, the concept of using opinions from a wide range of stakeholders to identify disclosure importance of IC attributes was employed in this research.

There have been several studies with respect to IC disclosure in the Chinese context, such as Xiao (2008) and Yi and Davey (2010). Both studies examine the level of IC disclosure by Chinese listed companies (50 largest and 49 dual-listed $\mathrm{A}$ and $\mathrm{H}$ share companies respectively), using the method of content analysis of corporate annual reports. However, there was no published research investigating the perceptions of stakeholders/users on the disclosure importance of IC attributes. Therefore, our paper contributes to minimal research on IC disclosure in this regard.

\section{Research Method}

Our research proceeded in two stages. In the first stage, the most significant IC attributes were identified on the basis of prior literature and a consultation process with a panel of Chinese stakeholders (Note 3) (who must be expert in IC and its disclosure) (Note 4). In the second stage, a questionnaire survey was designed to gather opinions of the stakeholder panel on the disclosure importance of the identified IC attributes.

\subsection{Selection of IC Attributes}

During the course of the first stage, relevant IC literature (i.e. Guthrie \& Petty, 2000; Goh \& Lim, 2004; Striukova et al., 2008; Yi \& Davey, 2010) were reviewed so as to determine the most commonly used and significant IC attributes. Accordingly, a number of attributes under three IC categories (Note 5) (internal capital, external capital and human capital) were identified in terms of the frequency in prior literature. Subsequently, the identified attributes were sent to the panel of Chinese stakeholders for comments. After consultation with the stakeholder panel, a total of 20 IC attributes, comprising 6 items in internal capital, 9 items in external capital and 5 items in human capital, were identified as the most significant IC attributes, which are shown in Table 1.

Table 1. Identified IC attributes

\begin{tabular}{ll}
\hline Internal capital & $\begin{array}{l}\text { research \& development; intellectual property; management philosophy/corporate culture; management } \\
\text { processes, information/networking systems; financial/investor relations }\end{array}$ \\
\hline External capital & $\begin{array}{l}\text { brands/reputation; customers; customer satisfaction/loyalty; marketing; distribution channels; business } \\
\text { collaborations; research collaborations; licensing agreements/franchising agreements/favorable contracts } \\
\text { employees; qualifications; education/training; work-related knowledge/competences; Entrepreneurial spirit }\end{array}$ \\
Human capital &
\end{tabular}

\subsection{Questionnaire Survey}

A questionnaire survey was then designed to gather opinions of the panelists on the disclosure importance of the IC attributes. For the content of the questionnaire, the researcher firstly gave instructions in regard to "who the researcher is", "what the objectives of the survey are", "how to fill in the questionnaire" and "the assurance of confidentiality". Although some information had been provided during the initial contact with the panelists, it was deemed formal and appropriate to inform them again. Next, the detailed questions were presented. In this section, the panelists were asked to rate the relative importance of IC items using an interval rating scale from one to five (Note 6). Despite a consensus regarding the IC attributes achieved at the first stage, the questionnaire still provided opportunities (in spaces) to allow the participants to add other attributes (and rate them simultaneously) if necessary. Comments or suggestions with respect to the overall survey were requested in the final section of the questionnaire. 


\section{Analysis and Results}

\subsection{Rating of IC Attributes}

To calculate the weighting (namely the value of disclosure importance) for a particular IC item, the ratings assigned to the item by the twenty panelists were summed and the total then divided by twenty to obtain a mean score. The higher the score of an IC item, the greater the importance that the item should be reported in the annual report.

The ratings for each IC item given by individual panel members are presented in Table 2. The spread of weightings as shown in the table reflects the diverse nature of the stakeholder panel, and the different objectives and focus of each panelist.

Amongst the IC items, 'intellectual property' was the most highly rated item by the panel with a mean score of 4.5 out of 5 (namely "extremely important to disclose"). The possible explanation is that this item is the most relevant item to IC not only from its name but also from its nature, and some elements of it (e.g. patents) can be recognized in the traditional accounting system. Other items such as 'brands/reputation', 'marketing', 'business collaborations', 'licensing agreements/franchising agreements/favorable contracts', 'research and development' (R\&D), and 'customer satisfaction/loyalty' were also highly rated by the panelists, all of which achieved an average score above 4 ("very important to disclose"). All these items other than 'research and development' belong to external capital. The high level of importance placed on external capital attributes maybe a result of the composition of the panel, where the majority of panelists (13 out of 20) represent external stakeholders (Note 7) of the company.

Three items ('management philosophy/corporate culture', 'information/networking systems' and 'education/training') were the least rated items with an identical average score of 3 ("moderately important to disclose"). That is, there were no IC items rated unimportant or little importance to disclose.

Table 2. Ratings for each IC attribute by the panelists

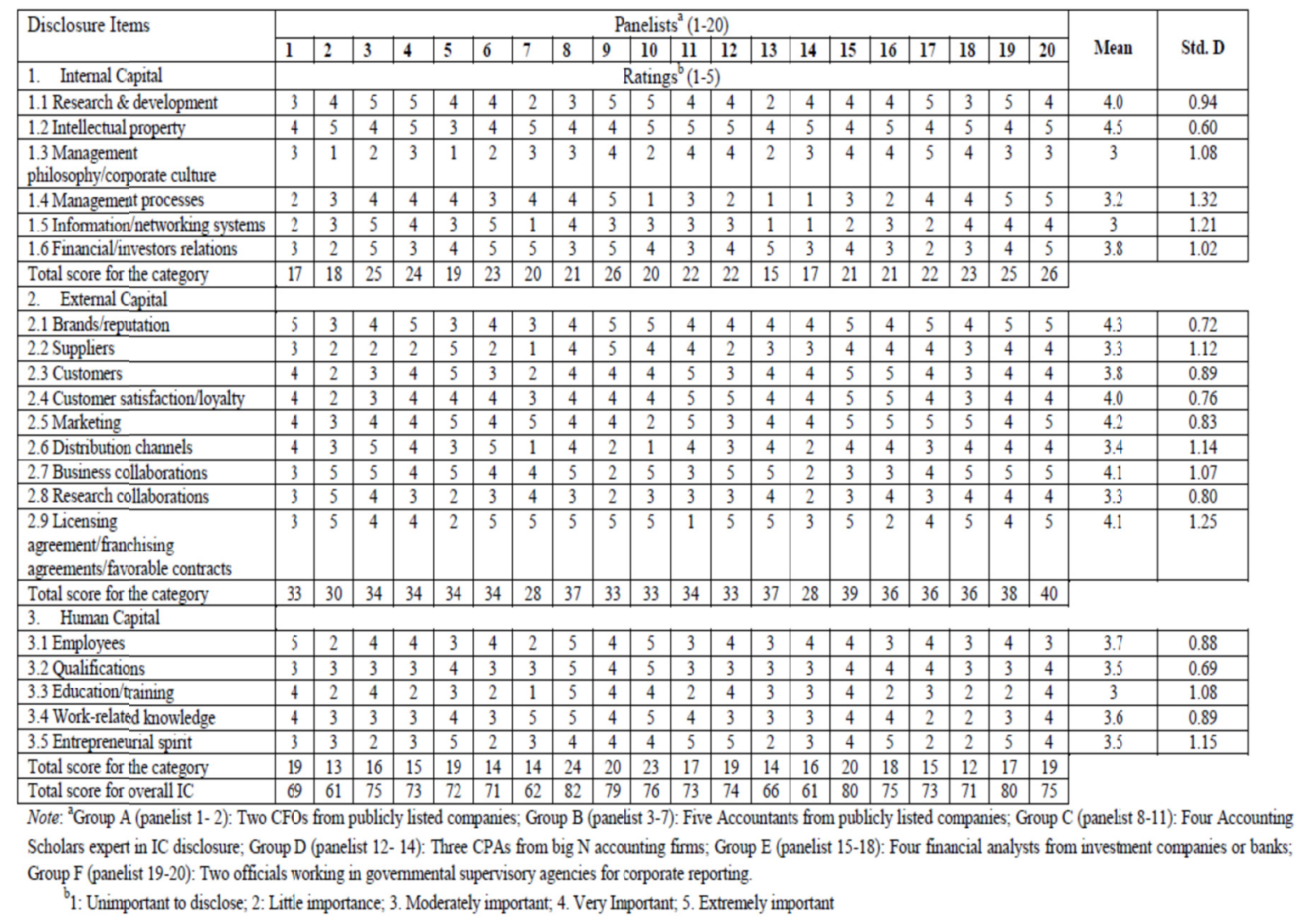




\subsection{Suggestions/Comments from the Panelists}

Meanwhile, we also obtained some suggestions and comments from the panelists in the survey. For example, a CFO from a publicly listed company (Panelist 2), made some comments with regard to attitudes of Chinese firms for accounting information disclosure. He stated that "no companies really want to disclose any further information (including IC) in their annual reports in China unless mandatorily required." This statement reflects the reality of IC disclosure in China to some extent.

Another panel member (Panelist 11), an accounting scholar from a university, commented on the disclosure attributes as follows:

"All of them (the IC attributes) should be disclosed theoretically. However it is a hard decision for many companies in practice due to the sensitive nature of some of them, such as the information relating to ongoing research and development projects. Once disclosed (such information), they may be imitated by the competitors quickly."

An official working in a governmental supervisory agency for corporate reporting (Panelist 20) argued that:

"It is unrealistic to require the listed firms to disclose all the IC items... The best way is to guide them (the listed companies) to report (the IC-related information) on a voluntary basis through developing certain IC disclosure guidelines."

Further, panelist three, an accountant preparing the annual report in a publicly listed company, expressed his expectations for IC reporting guidelines from the Chinese government as:

"...We acknowledge the benefits of IC reporting. However how to report and where to report remain problems for us. I hope that the government (financial reporting policy makers) could provide us some guidelines for that (IC reporting)."

Finally, a CPA (auditor) working in a big accounting firm (panelist 14) raised some concerns as to the auditing of IC-related information. He claimed that:

“...We do not expect Chinese firms to report a lot of IC-related information. Even if they report, we do not have an existing assurance system for this type of information. That's also a problem for us (to audit the IC-related information)."

These comments and suggestions offered us some valuable insights, and assisted us gain a deeper understanding in regard to perceptions of Chinese stakeholders on the disclosure of IC attributes in China.

\section{Concluding Comments}

Our research investigates perceptions of a panel of Chinese stakeholders on the disclosure importance of a set of significant IC attributes, by a questionnaire survey. The panel, comprising twenty members from six (annual report) user groups, represents a wide range of stakeholders, which avoids the bias imposed by only one-user group (i.e. financial analysts) often found in prior research. Although the ratings assigned by individual panel members may be varied, no attributes were rated as unimportant or little importance to disclose. Moreover, sixty percent of the attributes were rated as extremely or very important to disclose. These findings indicate that Chinese stakeholders have very strong demands on the disclosure of IC information, in particular that relating to intellectual property, brands/reputation, marketing, business collaborations, licensing agreements/franchising agreements/favorable contracts, research and development, and customer satisfaction/loyalty.

Our findings have some implications for Chinese companies and accounting policy makers. To begin, Chinese companies can devise their IC disclosure strategies in the light of the expectations of stakeholders on the disclosure of various IC attributes. According to stakeholder theory, if a company meets the expectations of various stakeholders, they should achieve a good relationship with them, and moreover “...gain support and approval from them (e.g. loyalty of customers) or distract their opposition and disapproval, which is beneficial for the organization (or company) to survive and succeed in a sustainable manner in society" (An et al., 2011, p. 575). Moreover, since there are no generally accepted IC reporting guidelines in China (as well as around the world), our findings provide some rationales for Chinese corporate reporting policy makers to develop such guidelines that could meet expectations of a wide range of Chinese user/stakeholder groups.

\subsection{Limitations}

We acknowledge that this research has some limitations. First, although the number of IC attributes was considered to be reasonable, some attributes (i.e. customers and employees) were too general and should be further classified into more sub-attributes (i.e. customer profitability and employee satisfaction). Second, 
although the expert/stakeholder panel represents a wide range of stakeholder groups, the size should be expanded to improve the validity of the research. Thirdly, our research is only a preliminary study in which it did not investigate if the actual IC disclosure practices of Chinese firms meet the expectations of stakeholders.

\subsection{Future Research}

Future research can employ the IC framework (20 items) developed in our research to gauge the extent, quality, and determinants of IC disclosure, in particular in the Chinese context. Moreover, future research could investigate the information gap between the expectations of Chinese stakeholders on the disclosure of IC-related information (namely the perceptions of Chinese stakeholders on the disclosure importance of various IC attributes) and the actual disclosure practices of Chinese companies.

\section{Acknowledgements}

The authors thank the comments offered by Professor Howard Davey (University of Waikato) and Professor Ian Eggleton (Victoria University of Wellington). This research was supported by the National Natural Science Foundation of China (No. 71172099) and the Ministry of Education of China (13YJC790098).

\section{References}

Abeysekera, I., \& Guthrie, J. (2005). An empirical Investigation of annual reporting trends of intellectual capital in Sri Lanka. Critical Perspectives on Accounting, 16(3), 151-163. http://dx.doi.org/10.1016/S1045-2354(03)00059-5

An, Y., Davey, H., \& Eggleton, I. R. C. (2011). Towards a comprehensive theoretical framework for voluntary IC disclosure. Journal of Intellectual Capital, 12(4), 571-585. http://dx.doi.org/10.1108/14691931111181733

Coy, D., \& Dixon, K. (2004). The public accountability index: Crating a parametric disclosure index for annual reports. The British Accounting Review, 36(1), 79-106. http://dx.doi.org/10.1016/j.bar.2003.10.003

Donaldson, T., \& Preston, L. E. (1995). The stakeholder theory of the corporation: Concepts, evidence and implications. Academy of Management Review, 20(1), 65-91. http://dx.doi.org/10. 5465/AMR.1995.9503271992

Freeman, R. E., Wicks, A. C., \& Parmar, B. (2004). Stakeholder theory and "the corporate objective revisited". Organization Science, 15(3), 364-369. http://dx.doi.org/10.1287/orsc.1040.0066

Goh, P., \& Lim, K. (2004). Disclosing intellectual capital in company annual reports: Evidence from Malaysia. Journal of Intellectual Capital, 5(3), 500-510. http://dx.doi.org/10.1108/14691930410550426

Guthrie, J., \& Petty, R. (2000). Intellectual capital: Australian annual reporting practices. Journal of Intellectual Capital, 1(3), 241-254. http://dx.doi.org/10.1108/14691930010350800

Hooks, J. (2000). Accountability in the retail and distribution sectors of the New Zealand electricity industry. Unpublished $\mathrm{PhD}$ thesis, University of Waikato, Hamilton, New Zealand.

Hooks, J., Coy, D., \& Davey, H. (2002). The information gap in annual reports. Accounting, Auditing and Accountability Journal, 15(4), 501-522. http://dx.doi.org/10.1108/09513570210440577

Khan, M. H., \& Ali, M. M. (2010). An empirical investigation and users' perceptions on intellectual capital reporting in banks: Evidence from Bangladesh. Journal of Human Resource Costing \& Accounting, 14(1), 48-69. http://dx.doi.org/10.1108/14013381011039799

Li, J., Pike, R., \& Haniffa, R. (2008). Intellectual capital disclosure and corporate governance structure in UK $\begin{array}{llll}\text { firms. Accounting } \text { and Business } & \text { Research, }\end{array}$ http://dx.doi.org/10.1080/00014788.2008.9663326

Nahapiet, J., \& Ghoshal, S. (1998). Social capital, intellectual capital, and the organizational advantage. Academy of Management Review, 23(2), 242-266. http://dx.doi.org/10.5465/AMR.1998.533225

Oliveira, L., Rodrigues, L. L., \& Craig, R. (2006). Firm-specific determinants of intangibles reporting: Evidence from the Portuguese stock market. Journal of Human Resource Costing \& Accounting, 10(1), 11-33.

Rashid, A. A., Ibrahim, M. K., Othman, R., \& See, K. F. (2012). IC disclosures in IPO prospectuses: Evidence from Malaysia. Journal of Intellectual Capital, 13(1), 57-80. http://dx.doi.org/10.1108/14691931211196213

Roberts, R. (1992). Determinants of corporate social responsibility disclosure. Accounting, Organizations and Society, 17(6), 595-612. http://dx.doi.org/10.1016/0361-3682(92)90015-K 
Schneider, A. \& Samkin, G. (2008). Intellectual capital reporting by the New Zealand Local Government Sector. Journal of Intellectual Capital, 9(3), 456-486. http://dx.doi.org/10.1108/14691930810892036

Stewart, T. A. (1997). Intellectual Capital: The New Wealth of Organizations. Doubleday Dell Publishing Group, New York.

Striukova, L., Unerman, J., \& Guthrie, J. (2008). Corporate reporting of intellectual capital: Evidence from UK companies. The British Accounting Review, 40(4), 297-313. http://dx.doi.org/10.1016/j.bar.2008.06.001

White, G., Lee, A., Yuningsih, Y., Nielsen, C., \& Bukh, P. N. (2010). The nature and extent of voluntary intellectual capital disclosures by Australian and UK biotechnology companies. Journal of Intellectual Capital, 11(4), 519-536. http://dx.doi.org/10.1108/14691931011085669

Xiao, H. F. (2008). Corporate reporting of intellectual capital: Evidence from China. The Business Review (Cambridge), 11(1), 124-129.

Yi, A., \& Davey, H. (2010). Intellectual capital disclosure in Chinese (mainland) companies. Journal of Intellectual Capital, 11(3), 326-347. http://dx.doi.org/10.1108/14691931011064572

\section{Notes}

Note 1. Including auditor, lender, regulator, preparer, academic, environmentalist, employee, consumer, financial reporter, industry consultant, consumers' advocate, director, energy trust, major electricity users, and financial analyst.

Note 2. Comprising internal citizens, external citizens, oversight agents, and report preparers.

Note 3. Comprising two CFOs and five accountants in preparing annual reports from publicly listed companies, four accounting scholars expert in IC disclosure, three CPAs from big $\mathrm{N}$ accounting firms, four financial analysts from investment companies or banks, and two officials working in governmental supervisory agencies for corporate reporting.

Note 4. The selected panelists must be expert in IC and its disclosure because (only) IC experts rather than general stakeholders could provide us insightful comments and suggestions to our research.

Note 5. The three-component framework is widely accepted and applied in the area. Internal capital represents the knowledge embedded in the organizational structure, processes, procedures, routines, systems and culture while external capital refers to the knowledge embedded in the relationships external to the organization (Pablos, 2002). Human capital represents the individual's knowledge such as qualification, skills, values and experiences within an organization.

Note 6. 1: unimportant to disclose; 2: of little importance to disclose; 3: moderately important to disclose; 4: very important to disclose; 5: extremely important to disclose.

Note 7. Including four accounting scholars, three CPAs, four financial analysts, and two officials.

\section{Copyrights}

Copyright for this article is retained by the author(s), with first publication rights granted to the journal.

This is an open-access article distributed under the terms and conditions of the Creative Commons Attribution license (http://creativecommons.org/licenses/by/3.0/). 